\title{
Haplotype-based study of the association of alcohol and acetaldehyde-metabolising genes with alcohol dependence (with or without comorbid anxiety symptoms) in a Cape Mixed Ancestry population
}

\author{
Andrew Crawford • Shareefa Dalvie • Sarah Lewis • \\ Anthony King • Israel Liberzon • George Fein • \\ Karestan Koenen • Rajkumar Ramesar • Dan J. Stein
}

Received: 28 September 2013 / Accepted: 6 February 2014 / Published online: 25 February 2014

(C) The Author(s) 2014. This article is published with open access at Springerlink.com

\begin{abstract}
Alcohol dependence (AD) has a large heritable component. Genetic variation in genes involved in the absorption and elimination of ethanol have been associated with AD. However, some of these polymorphisms are not present in an African population. Previous studies have reported that a type of $\mathrm{AD}$ which is characterized by anxious behaviour may be a genetically specific subtype of AD. We investigated whether variation in genes encoding cytochrome P450 2E1 (CYP2E1) or acetaldehyde-metabolising enzymes (ALDH1A1, ALDH2) might alter the risk of $\mathrm{AD}$, with and without symptoms of anxiety, in a Cape population with mixed ancestry. Eighty case control pairs (one with $\mathrm{AD}$, one without $\mathrm{AD}$ ) were
\end{abstract}

\section{A. Crawford $(\bowtie) \cdot S$. Lewis}

School of Social and Community Medicine, University of Bristol, Oakfield House, Oakfield Grove, Bristol BS8 2BN, UK

e-mail: andrew.crawford@bristol.ac.uk

S. Dalvie $\cdot$ R. Ramesar

MRC Human Genetics Research Unit, Division of Human Genetics, Institute of Infectious Disease and Molecular Medicine, University of Cape Town, Cape Town, South Africa

A. King $\cdot$ I. Liberzon

Department of Psychiatry, University of Michigan, Ann Arbor, USA

\section{Liberzon}

VA Ann Arbor Healthcare System, Ann Arbor, MI, USA

G. Fein

Neurobehavioral Research Inc, Honolulu, USA

K. Koenen

Mailman School of Public Health, Columbia University,

New York, USA

S. Dalvie $\cdot$ D. J. Stein

Department of Psychiatry and Mental Health, University of Cape

Town, Cape Town, South Africa recruited and individually matched for potential confounders. Genotype data were available for 29 single-nucleotide polymorphisms (SNPs) across the three genes. Linkage disequilibrium D' values were evaluated for all pairwise comparisons. Allele and haplotype frequencies were compared between cases and controls using a $\chi^{2}$ test. The ACAG haplotype in block 4 of the ALDH1A1 gene provided evidence of an association with $\mathrm{AD}(p=0.03)$ and weak evidence of an association with $\mathrm{AD}$ without symptoms of anxiety $(p=0.06)$. When a genetic score was constructed using SNPs showing nominal evidence of association with $\mathrm{AD}$, every extra risk allele increased the odds of $\mathrm{AD}$ by $35 \%$ (OR $1.35,95 \% \mathrm{CI}$ $1.08,1.68, p=0.008$ ) and the odds of having $\mathrm{AD}$ with anxiety symptoms increased by $53 \%$ (OR 1.53, 95\%CI 1.14, 2.05, $p=0.004$ ). Although our results are supported by previous studies in other populations, they must be interpreted with caution due to the small sample size and the potential influence of population stratification.

Keywords Alcohol dependence $\cdot$ Anxiety $\cdot$ Genetics

\section{Introduction}

Alcohol dependence (AD) is substantially heritable with studies estimating that heritability is between 50 and $70 \%$ (Heath et al. 1997; Hiroi and Agatsuma 2005; Ystrom et al. 2011; Young-Wolff et al. 2012). Genes associated with $\mathrm{AD}$ include those coding for enzymes involved in the absorption and elimination of ethanol such as alcohol dehydrogenase (ADH), aldehyde dehydrogenase (ALDH) and cytochrome P450 2E1 (CYP2E1) (Zakhari 2006; Edenberg 2007). Metabolism of ethanol consists of two rate 
limiting reactions (Zakhari 2006). Firstly, ethanol is converted to acetaldehyde, which is subsequently metabolized to acetate. The first step is predominantly catalysed by alcohol dehydrogenases (ADH), with minor roles for cytochrome P450 2E1 (CYP2E1) and catalase. In the second step, acetaldehyde is metabolised by aldehyde dehydrogenases (ALDH). Acetaldehyde is considerably more toxic than ethanol, and its accumulation leads to a highly aversive reaction that includes anxiety, facial flushing, nausea, and rapid heartbeat (Eriksson 2001).

Genetic variants that cause a build up of acetaldehyde, either by rapid ethanol metabolism or reduced acetaldehyde metabolism, have been found to be associated with lower risk for $\mathrm{AD}$ and heavy drinking (Edenberg 2007). The frequency of these genetic variants varies between ancestral groups (Edenberg 2012). The two polymorphisms that have been most strongly associated with AD in Asian populations, ADH1B Arg47His (rs1229984) and ALDH2 Glu487Lys (rs671), have little/no variation in one African population (Goedde et al. 1992).

$\mathrm{AD}$ is a heterogeneous disorder, highly comorbid with internalising disorders (Kessler et al. 1996). Various subtypes of $\mathrm{AD}$ have previously been described each with different reasons for developing an addiction, different withdrawal syndromes, different prognoses, and different responses to therapeutic approaches (Lesch et al. 1988). Research has suggested there may be an anxious subtype of AD characterized by high harm avoidance, high reward dependence, and low novelty-seeking behaviour (Cloninger 1987). More recently, reports have suggested this anxious $\mathrm{AD}$ may be a genetically specific subtype of AD (Lee et al. 2010). Therefore, if genetic markers could be used to identify this subtype of $\mathrm{AD}$, patient care could be improved by tailoring treatment accordingly.

The median age of onset for $\mathrm{AD}$ (23 years of age) is much later than for anxiety disorders (11 years of age) (Kessler et al. 2005). The risk of lifetime dependence to alcohol is far greater for individuals who start drinking at an earlier age (Grant and Dawson 1997). An adolescent cohort of individuals with AD indentifies the most serious cases of $\mathrm{AD}$, and anxiety symptoms would be expected to have been reported by this age.

We investigated whether variation in genes encoding CYP2E1 or acetaldehyde-metabolising enzymes (ALDH1A1, ALDH2) might alter the risk of $\mathrm{AD}$ in an adolescent Cape population with mixed ancestry by performing systematic haplotype association analyses to maximize the chances of capturing functional variation. We also investigated the association between a genotype risk score and $\mathrm{AD}$. Investigating genetic associations in different population groups is important in order to replicate and validate previous findings, or where results do not correlate it may indicate heterogeneity. Additionally, we investigated whether $\mathrm{AD}$ with or without comorbid symptoms of anxiety may be a genetically specific subtype of $\mathrm{AD}$.

\section{Methods}

Participants

Details of the participants have been reported previously (Ferrett et al. 2011). In brief, 80 case control pairs (one with $\mathrm{AD}$, one without $\mathrm{AD}$ ) from within the Cape Flats region (Cape Town, South Africa) were individually matched for age (within 1 year), gender (each group consisted of 47 females and 33 males), education level, language and socioeconomic status (SES). The average participant was aged 14.8 years (sd 0.76 ) and had completed 7.6 years (sd 0.82 ) of education. The sample reflected the sociodemographic profile of the Cape Flats population (100\% Coloured; Language, $69 \%$ Afrikaans, $31 \%$ English; $86 \%$ in households with formal housing; and $85 \%$ earning a gross annual income of less than ZAR 100 000). Exclusion criteria included, but were not limited to: mental retardation; lifetime DSM-IV Axis I diagnoses other than $\mathrm{AD}$ (including the following disorders: depressive, anxiety, psychotic, post-traumatic stress, eating, tic, attention-deficit/hyperactivity, oppositional defiant, and conduct); less than 6 years of formal education; and lack of proficiency in English or Afrikaans. Volunteers were screened for eligibility after written informed assent/consent was obtained from volunteers and parents or guardians.

The study protocol and procedures complied with and were conducted in strict adherence to the guidelines contained in the Declaration of Helsinki (2008). Full written approval to conduct the study was obtained from the Western Cape Education Department and the Research Ethics Committee of the Stellenbosch University Faculty of Health Sciences.

\section{Measures}

Alcohol use A revised version of the Timeline Followback (TLFB) procedure (Sobell and Sobell 1992), a semistructured, clinician-administered assessment of alcohol use and drinking patterns, was used in collaboration with the Kiddie Schedule for Affective Disorders and Schizophrenia Present and Lifetime Versions (K-SADS-PL) (Kaufman et al. 1997) to elicit alcohol-use data. A standard drink was defined as one beer or wine cooler, one glass of wine, or one $1.5-\mathrm{oz}$ shot of liquor (alone or in a mixed drink). AD was defined by a lifetime dosage in excess of 100 units plus a DSM-IV diagnosis of alcohol abuse or dependence. The control group were non-drinkers (who had never consumed alcohol) and light drinkers (lifetime dosage not exceeding 76 units of alcohol), with no history of $\mathrm{AD}$.

Psychopathology Total symptom counts from the K-SADSPL were recorded for generalised anxiety disorder. As previously mentioned, individuals with a diagnosis of anxiety disorders were excluded from the study. However, individuals 
reporting low levels of anxiety symptoms, not severe enough for a diagnosis of anxiety disorders, were included in the study. A binary variable was generated for the presence or absence of these anxiety symptoms in individuals with $\mathrm{AD}$ (anxious-AD). Of the 80 individuals with $\mathrm{AD}$, there were 59 individuals without any anxiety symptoms and 21 with anxiety symptoms.

Genotyping There were genotype data on a total of 29 singlenucleotide polymorphisms (SNPs) (16 SNPs in ALDH1A1, 7 SNPs in ALDH2, 6 SNPs in CYP2E1). Genotyping was carried out using a custom Illumina Infinium iSelect custom 6000 bead chip.

Genotype risk score We calculated a genotype risk score using all SNPs moderately associated with outcome (chisquare value greater than 1). The score was the unweighted sum of the number of risk alleles $(0,1$ or 2$)$ at each of these SNP loci. Separate genotype risk scores were created for the outcomes of $\mathrm{AD}$ and anxious-AD.

\section{Statistical analysis}

The genotype distributions for each SNP in the control group (without AD) were used to calculate deviation from HardyWeinberg equilibrium (HWE) using a $\chi^{2}$ test, and those SNP's which did show evidence of deviation were excluded from further analysis. Linkage disequilibrium (LD) $D^{\prime}$ values were evaluated for all marker pairs. Customised haplotype blocks were defined in Haploview version 4.2 (Barrett et al. 2005). Allele and haplotype frequencies were compared between cases and controls using a $\chi^{2}$ test. Logistic regression models were used to investigate the association between genotype risk score and the outcomes of AD, or AD with anxiety symptoms. A Bonferroni correction was applied to address the issues associated with multiple testing (Bland and Altman 1995). A power calculation was performed using the Quanto software (Version 1.2.4) (Gauderman and Morrison 2006). Statistical analyses were performed using Haploview version 4.2 (Barrett et al. 2005) and Stata version 12.1 (StataCorp 2011).

\section{Results}

There was evidence that one SNP (rs348457) deviated from HWE $(p<0.001)$ and there was no genetic variation in another SNP (rs671). Both these SNPs were excluded from our analyses. This left a total of 27 SNPs in the analysis (15 for ALDH1A1, 6 for ALDH2, 6 for CYP2E1). The allele frequencies for the 27 SNPs are presented in Table 1. To correct for the multiple testing of 27 SNPs in two disease models, a threshold level of significance was calculated as $p<0.0009$. This is a conservative estimate due to the LD between SNPs.
Given the number of tests, there was no evidence of any associations other than one would expect by chance.

Linkage disequilibrium

The extent of LD between the SNPs was determined for ALDH1A1 (Fig. 1), ALDH2 (Fig. 2) and CYP2E1 (Fig. 3).

Alcohol dependence analysis

A total of 160 individuals were included in the analysis (80 with AD, 80 without AD). There was some evidence of an association between AD and rs6413419 in the CYP2E1 gene $(p=0.04)$ (Table 1). In the haplotype analysis there was some evidence of an association with the ACAG haplotype in block 4 of the ALDH1A1 gene $(p=0.03)$ (Table 2).

Alcohol dependence with anxiety symptoms analysis

A total of 80 individuals with AD were included in the analysis (21 with anxiety symptoms, 59 without anxiety symptoms). There was weak evidence of an association with anxious-AD and rs63319 of the ALDH1A1 gene $(p=0.10)$ (Table 1). In the haplotype analysis there was weak evidence of an association with the ACAG haplotype in block 4 of the ALDH1A1 gene $(p=0.06)$ (Table 2).

\section{Genotype risk score}

There were 8 SNPs (4 SNPs in ALDH1A1, 2 SNPs in ALDH2, 2 SNPs in CYP2E1) associated with AD that were included in this genotype risk score. This score ranged from 5 to 13 . For every increase in genotype risk score (ie. for every extra risk allele) the odds of AD increased by $35 \%$ (OR 1.35, 95\%CI 1.08, 1.68, $p=0.008)$.

There were 8 SNPs (3 SNPs in ALDH1A1, 2 SNPs in ALDH2, 3 SNPs in CYP2E1) associated with anxious-AD that were included in this genotype risk score. This score ranged from 5 to 16. For every increase in genotype risk score (ie. for every extra risk allele) the odds of having $\mathrm{AD}$ with anxiety symptoms (rather than $\mathrm{AD}$ without anxiety symptoms) increased by $53 \%$ (OR 1.53, 95\%CI 1.14, 2.05, $p=0.004)$. The effect of both genotype risk scores appeared to be linear, although interpretation is limited due to a small number of individuals at the extremes.

Power calculation

We performed a post hoc statistical power and sample size analysis. Statistical power is defined as the probability of rejecting the null hypothesis while the alternative hypothesis is true. The results vary for each SNP investigated but assuming an allele frequency of 0.9 (rs6413419), a population risk of 
Table 1 Allele frequencies and associations with alcohol dependence or alcohol dependence with anxiety symptoms

\begin{tabular}{|c|c|c|c|c|c|c|c|c|}
\hline \multirow[t]{2}{*}{ Gene } & \multirow[t]{2}{*}{ SNP } & \multirow[t]{2}{*}{ Allele } & \multicolumn{3}{|l|}{$\mathrm{AD}$} & \multicolumn{3}{|l|}{ AD with anxiety symptoms } \\
\hline & & & Case, control frequencies & Chi square & $P$ value & Case, control frequencies & Chi square & $P$ value \\
\hline \multirow[t]{15}{*}{ ALDH1A1 } & rs8187998 & $\mathrm{A}$ & $1.000,0.994$ & 1.00 & 0.32 & $1.000,1.000$ & - & - \\
\hline & rs1888202 & $\mathrm{C}$ & $0.625,0.619$ & 0.01 & 0.91 & $0.548,0.653$ & 1.46 & 0.23 \\
\hline & rs63319 & A & $0.538,0.531$ & 0.01 & 0.91 & $0.429,0.576$ & 2.72 & 0.10 \\
\hline & rs8187974 & A & $0.006,0.000$ & 1.00 & 0.32 & $0.000,0.008$ & 0.36 & 0.55 \\
\hline & rs2773806 & G & $0.256,0.206$ & 1.13 & 0.29 & $0.262,0.254$ & 0.01 & 0.92 \\
\hline & rs1424482 & G & $0.506,0.494$ & 0.05 & 0.82 & $0.500,0.508$ & 0.01 & 0.92 \\
\hline & rs8187876 & G & $0.850,0.844$ & 0.02 & 0.88 & $0.857,0.847$ & 0.02 & 0.88 \\
\hline & rs11143429 & A & $0.644,0.631$ & 0.05 & 0.82 & $0.643,0.644$ & 0.00 & 0.99 \\
\hline & rs6560311 & $\mathrm{C}$ & $0.719,0.669$ & 0.94 & 0.33 & $0.738,0.712$ & 0.11 & 0.75 \\
\hline & rs2249978 & G & $0.519,0.506$ & 0.05 & 0.82 & $0.500,0.525$ & 0.08 & 0.78 \\
\hline & rs1418187 & G & $0.612,0.588$ & 0.21 & 0.65 & $0.571,0.627$ & 0.41 & 0.52 \\
\hline & rs4745209 & G & $0.338,0.325$ & 0.06 & 0.81 & $0.381,0.322$ & 0.48 & 0.49 \\
\hline & rs7860980 & $\mathrm{C}$ & $0.956,0.938$ & 0.56 & 0.45 & $0.952,0.958$ & 0.02 & 0.89 \\
\hline & rs4406477 & A & $0.569,0.556$ & 0.05 & 0.82 & $0.548,0.576$ & 0.10 & 0.75 \\
\hline & rs11143443 & G & $0.138,0.100$ & 1.08 & 0.30 & $0.071,0.161$ & 2.10 & 0.15 \\
\hline \multirow[t]{6}{*}{ ALDH2 } & rs2238151 & G & $0.219,0.219$ & 0.00 & 0.99 & $0.857,0.754$ & 1.92 & 0.17 \\
\hline & rs2238152 & A & $0.162,0.138$ & 0.39 & 0.53 & $0.167,0.161$ & 0.01 & 0.93 \\
\hline & rs4648328 & A & $0.162,0.131$ & 0.62 & 0.43 & $0.167,0.161$ & 0.01 & 0.93 \\
\hline & rs7311852 & $\mathrm{C}$ & $0.031,0.006$ & 2.72 & 0.10 & $0.024,0.034$ & 0.10 & 0.75 \\
\hline & rs4646778 & A & $0.162,0.138$ & 0.39 & 0.53 & $0.167,0.161$ & 0.01 & 0.93 \\
\hline & rs7296651 & $\mathrm{C}$ & $0.594,0.512$ & 2.14 & 0.14 & $0.667,0.568$ & 1.26 & 0.26 \\
\hline \multirow[t]{6}{*}{ CYP2E1 } & rs3813865 & G & $0.825,0.819$ & 0.02 & 0.88 & $0.857,0.814$ & 0.41 & 0.52 \\
\hline & rs3813867 & G & $0.056,0.050$ & 0.06 & 0.80 & $0.024,0.068$ & 1.13 & 0.29 \\
\hline & rs915906 & A & $0.544,0.488$ & 1.01 & 0.31 & $0.619,0.517$ & 1.30 & 0.25 \\
\hline & rs6413419 & G & $0.931,0.862$ & 4.09 & 0.04 & $0.929,0.932$ & 0.01 & 0.94 \\
\hline & rs743535 & G & $0.831,0.819$ & 0.09 & 0.77 & $0.857,0.822$ & 0.27 & 0.60 \\
\hline & rs2515642 & $\mathrm{A}$ & $0.569,0.569$ & 0.00 & 0.99 & $0.524,0.398$ & 1.99 & 0.16 \\
\hline
\end{tabular}

$A D$ alcohol dependence. A total of 160 individuals were included in the $\mathrm{AD}$ analysis ( 80 with $\mathrm{AD}, 80$ without $\mathrm{AD}$ ). A total of $80 \mathrm{AD}$ individuals were included in the $\mathrm{AD}$ with anxiety analysis ( 21 with anxiety symptoms, 59 without anxiety symptoms)

0.1 , an additive genetic model, an odds ratio of 3 (aa v. AA) and significance set at $5 \%$, we had $27 \%$ power. Using the same assumptions but setting the power to $80 \%$ we would need a sample size approximately five times the size of the current study (or ten times the size for the anxious-AD analysis).

\section{Discussion}

Main findings and comparisons with the literature

Although AD is prevalent in South Africa (Williams et al. 2008; Peltzer et al. 2011) there has been a paucity of previous research investigating genetic variants associated with this phenotype in a South African population. The ACAG haplotype in block 4 of the ALDH1A1 gene had a frequency of
$6.9 \%$ in our cohort and provided some evidence of an association with $\mathrm{AD}$. This haplotype was more frequent in individuals with $\mathrm{AD}$ than controls $(10 \%$ v. $3.8 \%, p=0.03)$ and more frequent in individuals with $\mathrm{AD}$ but without anxiety symptoms than individuals with $\mathrm{AD}$ and anxiety symptoms (12.7\% v. $2.4 \%, p=0.06)$. Therefore, it is possible that this haplotype may identify non-anxious $\mathrm{AD}$ as a genetically specific subtype of AD. There were also encouraging findings with regard to the genotype risk score.

The association between AD and the ACAG haplotype was driven by rs11143443. This SNP is located upstream of the $5^{\prime}$ promoter region of the ALDH1A1 gene and has previously been associated with $\mathrm{AD}$ in an African American population (Liu et al. 2011). Genetic variation in the promoter region has been reported to affect ALDH1A1 gene expression (Spence et al. 2003), although to our knowledge no such gene expression data exist for this particular SNP. Liu et al. (Liu et al. 2011) 
Fig. 1 Haplotype block structure for the ALDH1A1 gene on chromosome 9. Haplotype blocks are outlined. Figures represent $\mathrm{D}^{\prime}$

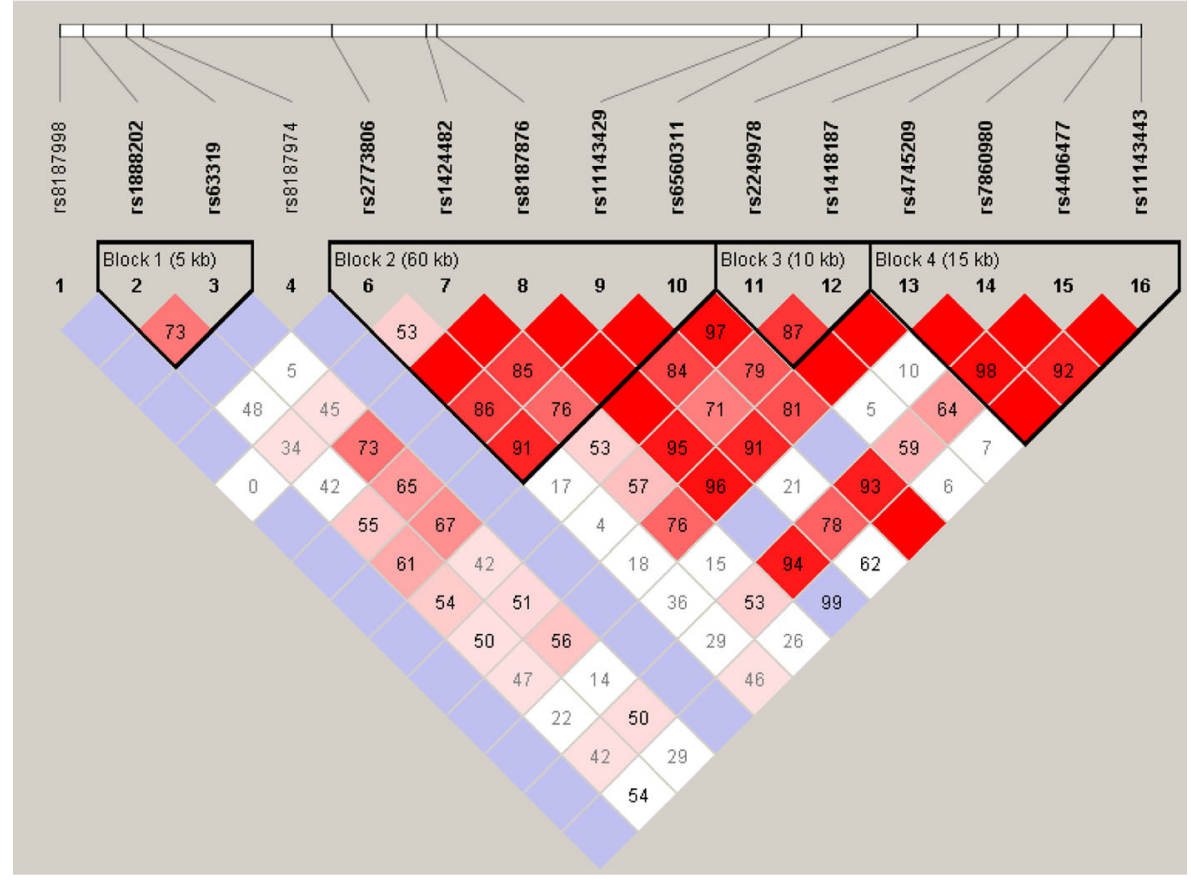

also reported evidence of an association between $\mathrm{AD}$ and a haplotype in ALDH2, driven by rs7311852. The same SNP provided weak evidence of an association with $\mathrm{AD}$ in our data. However, the authors report that the positive association was influenced by population stratification.

The Cape Mixed Ancestry group, which has been shown to have the greatest level of intercontinental admixture compared to any other international population group, consists of individuals of Khoesan, Bantu-speaking African, European and Asian ethnicity (Tishkoff et al. 2009; de Wit et al. 2010). A principal components analysis, using genetic markers across the genome, would be required to determine whether this cohort consists of a single genetic population, and thus

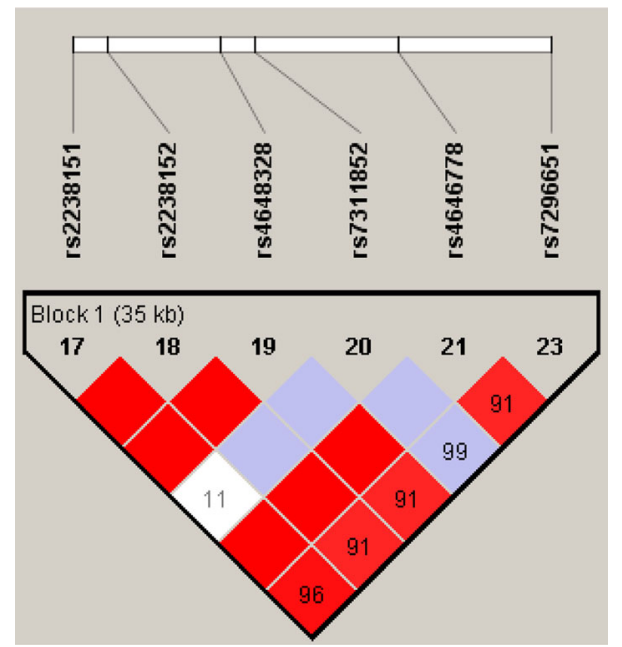

Fig. 2 Haplotype block structure for the ALDH2 gene on chromosome 12. Haplotype blocks are outlined. Figures represent $\mathrm{D}^{\prime}$ whether our associations are influenced by population stratification. Comparing the allele frequencies of individuals in this study with populations in the HapMap project (Gibbs et al. 2003) showed the frequencies to be intermediate between the Utah residents with ancestry from northern and western Europe (CEU) and the Yoruba in Ibadan, Nigeria (YRI) (data not shown).

\section{Strengths, limitations and future directions}

The main limitation of this study is the small sample size which is further compounded in our pre-specified subgroup analysis of AD with or without anxiety symptoms. Therefore,

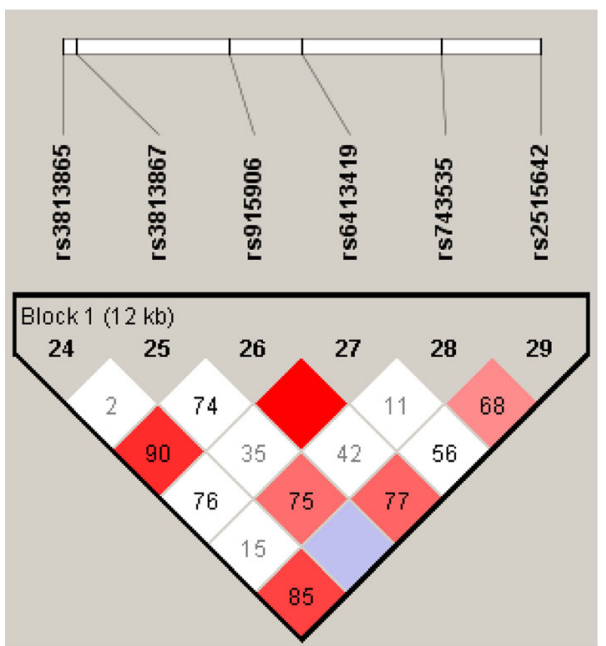

Fig. 3 Haplotype block structure for the CYP2E1 gene on chromosome 10. Haplotype blocks are outlined. Figures represent $\mathrm{D}^{\prime}$ 
Table 2 ALDH1A1, ALDH2 and CYP2E1 haplotype frequencies and associations with alcohol dependence or alcohol dependence with anxiety symptoms

\begin{tabular}{|c|c|c|c|c|c|c|c|c|c|}
\hline \multirow[t]{2}{*}{ Gene } & \multirow[t]{2}{*}{ Block } & \multirow[t]{2}{*}{ Haplotype } & \multirow[t]{2}{*}{ Freq. } & \multicolumn{3}{|l|}{$\mathrm{AD}$} & \multicolumn{3}{|l|}{ AD with anxiety symptoms } \\
\hline & & & & Case control frequencies & Chi square & $P$ value & Case control frequencies & Chi square & $P$ value \\
\hline \multirow[t]{17}{*}{ ALDH1A1 } & \multirow[t]{4}{*}{ Block1 } & $\mathrm{CA}$ & 0.48 & $0.491,0.469$ & 0.16 & 0.69 & $0.395,0.525$ & 2.12 & 0.15 \\
\hline & & $\mathrm{GC}$ & 0.32 & $0.329,0.319$ & 0.04 & 0.85 & $0.418,0.297$ & 2.08 & 0.15 \\
\hline & & $\mathrm{CC}$ & 0.14 & $0.134,0.150$ & 0.17 & 0.68 & $0.153,0.127$ & 0.18 & 0.67 \\
\hline & & GA & 0.05 & $0.046,0.062$ & 0.40 & 0.53 & $0.034,0.051$ & 0.20 & 0.66 \\
\hline & \multirow[t]{5}{*}{ Block 2} & AAGGC & 0.33 & $0.332,0.332$ & 0.00 & 0.99 & $0.355,0.324$ & 0.13 & 0.72 \\
\hline & & GGGAC & 0.16 & $0.191,0.137$ & 1.72 & 0.19 & $0.198,0.189$ & 0.02 & 0.89 \\
\hline & & AGAAA & 0.15 & $0.150,0.156$ & 0.02 & 0.88 & $0.143,0.153$ & 0.02 & 0.88 \\
\hline & & AGGAA & 0.10 & $0.089,0.108$ & 0.33 & 0.56 & $0.075,0.094$ & 0.15 & 0.70 \\
\hline & & AAGAC & 0.08 & $0.089,0.066$ & 0.56 & 0.46 & $0.042,0.105$ & 1.55 & 0.21 \\
\hline & \multirow[t]{3}{*}{ Block 3} & GG & 0.49 & $0.503,0.472$ & 0.31 & 0.58 & $0.496,0.505$ & 0.01 & 0.91 \\
\hline & & $\mathrm{AA}$ & 0.38 & $0.372,0.378$ & 0.02 & 0.90 & $0.424,0.353$ & 0.68 & 0.41 \\
\hline & & $\mathrm{AG}$ & 0.11 & $0.110,0.116$ & 0.03 & 0.87 & $0.076,0.122$ & 0.67 & 0.41 \\
\hline & \multirow[t]{5}{*}{ Block 4} & ACAA & 0.44 & $0.425,0.456$ & 0.32 & 0.57 & $0.476,0.406$ & 0.61 & 0.44 \\
\hline & & GCGA & 0.32 & $0.324,0.324$ & 0.00 & 0.99 & $0.380,0.305$ & 0.81 & 0.37 \\
\hline & & ACGA & 0.11 & $0.100,0.119$ & 0.29 & 0.59 & $0.072,0.111$ & 0.51 & 0.48 \\
\hline & & ACAG & 0.07 & $0.100,0.038$ & 4.88 & 0.03 & $0.024,0.127$ & 3.68 & 0.06 \\
\hline & & AAAG & 0.05 & $0.037,0.062$ & 1.05 & 0.30 & $0.048,0.034$ & 0.17 & 0.68 \\
\hline \multirow[t]{4}{*}{ ALDH2 } & \multirow[t]{4}{*}{ Block 1} & GCGGCC & 0.39 & $0.402,0.384$ & 0.11 & 0.74 & $0.479,0.375$ & 1.42 & 0.23 \\
\hline & & GCGGCG & 0.23 & $0.193,0.260$ & 2.03 & 0.15 & $0.189,0.195$ & 0.01 & 0.93 \\
\hline & & ACGGCG & 0.21 & $0.211,0.212$ & 0.00 & 0.98 & $0.141,0.236$ & 1.66 & 0.20 \\
\hline & & GAAGAC & 0.14 & $0.153,0.122$ & 0.65 & 0.42 & $0.162,0.149$ & 0.04 & 0.84 \\
\hline \multirow[t]{5}{*}{ CYP2E1 } & \multirow[t]{5}{*}{ Block 1} & GCAGGA & 0.38 & $0.390,0.371$ & 0.12 & 0.73 & $0.472,0.360$ & 1.63 & 0.20 \\
\hline & & GCGGGG & 0.15 & $0.157,0.150$ & 0.03 & 0.87 & $0.130,0.167$ & 0.33 & 0.57 \\
\hline & & CCGGGG & 0.11 & $0.124,0.104$ & 0.32 & 0.57 & $0.082,0.139$ & 0.91 & 0.34 \\
\hline & & GCGAGG & 0.07 & $0.050,0.094$ & 2.30 & 0.13 & $0.048,0.051$ & 0.01 & 0.93 \\
\hline & & GCAGGG & 0.07 & $0.067,0.070$ & 0.02 & 0.90 & $0.096,0.056$ & 0.79 & 0.37 \\
\hline
\end{tabular}

$A D$ alcohol dependence. The table lists haplotypes that have a frequency greater than $5 \%$. A total of 160 individuals were included in the $\mathrm{AD}$ analysis ( 80 with $\mathrm{AD}, 80$ without $\mathrm{AD})$. A total of $80 \mathrm{AD}$ individuals were included in the $\mathrm{AD}$ with anxiety analysis (21 with anxiety symptoms, 59 without anxiety symptoms)

our findings must be interpreted with caution and should be considered preliminary. This is especially true given that there was no evidence of any association other than that which one would expect by chance. However, we limited our analyses to focus on three biologically relevant genes and have been clear on the tests that have been performed which is generally more important when dealing with multiple comparisons (Perneger 1998).

This adolescent cohort contained extremely well defined cases of $\mathrm{AD}$ as individuals with a diagnosis of comorbid generalised anxiety disorder were excluded from the study. Therefore, our power to identify a genetically specific subtype of non-anxious $\mathrm{AD}$ will be greater than other cohorts of a similar size. Our power calculation clearly indicates that larger studies are required in this area. A potential limitation of this selective cohort is that the results may not be generalisable to the general population where $\mathrm{AD}$ tends to be highly comorbid with other disorders. Additionally, as this is an adolescent cohort, and the median age of onset for AD is 23 years of age, it is possible that individuals included as controls in this study may go on to develop AD. However, AD is inversely associated with age of first drink and so individuals with $\mathrm{AD}$ in this cohort are likely to have a more severe phenotype than a control individual that goes onto develop $\mathrm{AD}$ at a later stage (Grant and Dawson 1997).

For some SNPs the evidence of an association was stronger in the $\mathrm{AD}$ analysis than in the anxious-AD analysis. This may be because this is a marker associated with $\mathrm{AD}$ in general rather than with a specific subtype of AD. Alternatively, this may also be explained by the reduction in sample size between the two analyses. This can be seen for the SNP rs7296651 where the effect size in the $\mathrm{AD}$ analysis is less extreme, but the 
strength of evidence for the association is stronger than in the anxious-AD analysis (AD analysis: $\mathrm{OR} 0.71,95 \% \mathrm{CI} 0.45$ to $1.12, p=0.14$, compared with anxious-AD analysis: OR 0.62 , $95 \%$ CI 0.28 to $1.37, p=0.24$ ). The same set of individuals were used in the discovery and testing of the genetic risk scores therefore, although we observed relatively large effect sizes future work could look to validate these findings in an independent sample.

This study increases the body of evidence investigating genetic variants and $\mathrm{AD}$ in a genetically admixed population. It is important to investigate this type of population in order to replicate previous findings, as well as attempting to identify genetic variants for complex disorders (de Wit et al. 2010). Meta-analyses of genetic studies will be needed to identify genetically-specific subtypes of $\mathrm{AD}$, potentially providing insights into the biological mechanism of these disorders.

Acknowledgments This paper was supported by the EU Marie Curie International Staff Exchange Scheme grant for the European South African Research Network in Anxiety Disorders (EUSARNAD) (PIRSESGA-2010-269213). Dan Stein, Shareefa Dalvie and Rajkumar Ramesar are supported by the Medical Research Council of South Africa.

Conflict of interest No potential conflicts of interest exist.

Open Access This article is distributed under the terms of the Creative Commons Attribution License which permits any use, distribution, and reproduction in any medium, provided the original author(s) and the source are credited.

\section{References}

Barrett JC, Fry B, Maller J, Daly MJ (2005) Haploview: analysis and visualization of LD and haplotype maps. Bioinformatics $21: 263-265$

Bland JM, Altman DG (1995) Multiple significance tests: the Bonferroni method. BMJ 310:170

Cloninger CR (1987) Neurogenetic adaptive-mechanisms in alcoholism. Science 236:410-416

de Wit E, Delport W, Rugamika CE, Meintjes A, Moeller M, van Helden PD, Seoighe C, Hoal EG (2010) Genome-wide analysis of the structure of the South African Coloured Population in the Western Cape. Hum Genet 128:145-153

Edenberg HJ (2007) The genetics of alcohol metabolism - role of alcohol dehydrogenase and aldehyde dehydrogenase variants. Alcohol Res Health 30:5-13

Edenberg HJ (2012) Genes contributing to the development of alcoholism an overview. Alcohol Res Curr Rev 34:336-338

Eriksson CJP (2001) The role of acetaldehyde in the actions of alcohol (Update 2000). Alcohol Clin Exp Res 25:15S-32S

Ferrett HL, Cuzen NL, Thomas KGF, Carey PD, Stein DJ, Finn PR, Tapert SF, Fein G (2011) Characterization of South African adolescents with alcohol use disorders but without psychiatric or polysubstance comorbidity. Alcoholism 35:1705-1715

Gauderman WJ, Morrison JM (2006) QUANTO 1.1: A computer program for power and sample size calculations for genetic-epidemiology studies. http://hydra.usc.edu/gxe. Accessed 15 Jan 2014

Gibbs RA, Belmont JW, Hardenbol P, Willis TD, Yu FL, Yang HM, Ch'ang LY, Huang W, Liu B, Shen Y, Tam PKH, Tsui LC, Waye
MMY, Wong JTF, Zeng CQ, Zhang QR, Chee MS, Galver LM, Kruglyak S, Murray SS, Oliphant AR, Montpetit A, Hudson TJ, Chagnon F, Ferretti V, Leboeuf M, Phillips MS, Verner A, Kwok PY, Duan SH, Lind DL, Miller RD, Rice JP, Saccone NL, Taillon-Miller P, Xiao M, Nakamura Y, Sekine A, Sorimachi K, Tanaka T, Tanaka Y, Tsunoda T, Yoshino E, Bentley DR, Deloukas P, Hunt S, Powell D, Altshuler D, Gabriel SB, Qiu RZ, Ken A, Dunston GM, Kato K, Niikawa N, Knoppers BM, Foster MW, Clayton EW, Wang VO, Watkin J, Gibbs RA, Belmont JW, Sodergren E, Weinstock GM, Wilson RK, Fulton LL, Rogers J, Birren BW, Han H, Wang HG, Godbout M, Wallenburg JC, L'Archeveque P, Bellemare G, Todani K, Fujita T, Tanaka S, Holden AL, Lai EH, Collins FS, Brooks LD, McEwen JE, Guyer MS, Jordan E, Peterson JL, Spiegel J, Sung LM, Zacharia LF, Kennedy K, Dunn MG, Seabrook R, Shillito M, Skene B, Stewart JG, Valle DL, Clayton EW, Jorde LB, Belmont JW, Chakravarti A, Cho MK, Duster T, Foster MW, Jasperse M, Knoppers BM, Kwok PY, Licinio J, Long JC, Marshall PA, Ossorio PN, Wang VO, Rotimi CN, Royal CDM, Spallone P, Terry SF, Lander ES, Lai EH, Nickerson DA, Abecasis GR, Altshuler D, Bentley DR, Boehnke M, Cardon LR, Daly MJ, Deloukas P, Douglas JA, Gabriel SB, Hudson RR, Hudson TJ, Kruglyak L, Kwok PY, Nakamura Y, Nussbaum RL, Royal CDM, Schaffner SF, Sherry ST, Stein LD, Tanaka T, Int HapMap C (2003) The International HapMap Project. Nature 426:789-796

Goedde HW, Agarwal DP, Fritze G, Meiertackmann D, Singh S, Beckmann G, Bhatia K, Chen LZ, Fang B, Lisker R, Paik YK, Rothhammer F, Saha N, Segal B, Srivastava LM, Czeizel A (1992) Distribution of ADH2 and ALDH2 genotypes in different populations. Hum Genet 88:344-346

Grant BF, Dawson DA (1997) Age at onset of alcohol use and its association with DSM-IV alcohol abuse and dependence: results from the National Longitudinal Alcohol Epidemiologic Survey. J Subst Abus 9:103-110

Heath AC, Bucholz KK, Madden PAF, Dinwiddie SH, Slutske WS, Bierut LJ, Statham DJ, Dunne MP, Whitfield JB, Martin NG (1997) Genetic and environmental contributions to alcohol dependence risk in a national twin sample: consistency of findings in women and men. Psychol Med 27:1381-1396

Hiroi N, Agatsuma S (2005) Genetic susceptibility to substance dependence. Mol Psychiatry 10:336-344

Kaufman J, Birmaher B, Brent D, Rao U, Flynn C, Moreci P, Williamson D, Ryan N (1997) Schedule for affective disorders and schizophrenia for school-age children present and lifetime version (K-SADSPL): initial reliability and validity data. J Am Acad Child Adolesc Psychiatry 36:980-988

Kessler RC, Nelson CB, McGonagle KA, Edlund MJ, Frank RG, Leaf PJ (1996) The epidemiology of co-occurring addictive and mental disorders: implications for prevention and service utilization. Am J Orthopsychiatry 66:17-31

Kessler RC, Berglund P, Demler O, Jin R, Walters EE (2005) Lifetime prevalence and age-of-onset distributions' of DSM-IV disorders in the national comorbidity survey replication. Arch Gen Psychiatry 62:593-602

Lee S-Y, Hahn C-Y, Lee J-F, Huang S-Y, Chen S-L, Kuo P-H, Lee IH, Yeh TL, Yang YK, Chen S-H, Ko H-C, Lu R-B (2010) MAOA interacts with the ALDH2 gene in anxiety-depression alcohol dependence. Alcoholism 34:1212-1218

Lesch OM, Dietzel M, Musalek M, Walter H, Zeiler K (1988) The course of alcoholism. Long-term prognosis in different types. Forensic Sci Int 36:121-138

Liu J, Zhou Z, Hodgkinson CA, Yuan Q, Shen P-H, Mulligan CJ, Wang A, Gray RR, Roy A, Virkkunen M, Goldman D, Enoch M-A (2011) Haplotype-based study of the association of alcohol-metabolizing genes with alcohol dependence in four independent populations. Alcoholism 35:304-316 
Peltzer K, Davids A, Njuho P (2011) Alcohol use and problem drinking in South Africa: findings from a national population-based survey. Afr J Psychiatry 14:30-37

Perneger TV (1998) What's wrong with Bonferroni adjustments. Br Med J 316:1236-1238

Sobell LC, Sobell MB (1992) Timeline follow-back: A technique for assessing self reported alcohol consumption. In: Litten RZ, Allen JP (eds) Measuring alcohol consumption: Psychosocial and biochemical methods. Humana Press, Totowa, pp 41-72

Spence JP, Liang TB, Eriksson CJP, Taylor RE, Wall TL, Ehlers CL, Carr LG (2003) Evaluation of aldehyde dehydrogenase 1 promoter polymorphisms identified in human populations. Alcoholism 27: 1389-1394

StataCorp (2011) Stata statistical software. StataCorp LP, College Station

Tishkoff SA, Reed FA, Friedlaender FR, Ehret C, Ranciaro A, Froment A, Hirbo JB, Awomoyi AA, Bodo J-M, Doumbo O, Ibrahim M, Juma AT, Kotze MJ, Lema G, Moore JH, Mortensen H, Nyambo TB, Omar SA, Powell K, Pretorius GS, Smith MW,
Thera MA, Wambebe C, Weber JL, Williams SM (2009) The genetic structure and history of Africans and African Americans. Science 324:1035-1044

Williams DR, Herman A, Stein DJ, Heeringa SG, Jackson PB, Moomal H, Kessler RC (2008) Twelve-month mental disorders in South Africa: prevalence, service use and demographic correlates in the population-based South African Stress and Health Study. Psychol Med 38:211-220

World Medical Association (2008) Declaration of Helsinki. Ethical principles for medical research involving human subjects. 59th WMA General Assembly. Seoul, South Korea

Young-Wolff KC, Chereji E, Prescott CA (2012) Heritability of alcohol dependence is similar in women and men. Evid-Based Ment Health 15:57

Ystrom E, Reichborn-Kjennerud T, Aggen SH, Kendler KS (2011) Alcohol dependence in men: reliability and heritability. Alcoholism 35:1716-1722

Zakhari S (2006) Overview: how is alcohol metabolized by the body? Alcohol Res Health 29:245-254 